\title{
Consolidation of Reactor Physics Education - the Khalifa University Student Field Trips Case Study
}

\author{
Saeed A. Alameri ${ }^{1 *}$, Mohammad Alrwashdeh ${ }^{1}$, Philip Beeley ${ }^{1}$, Myung-Hyun Kim ${ }^{2}$, and \\ Kenan Unlu ${ }^{3}$
}

${ }^{1}$ Department of Nuclear Engineering, Khalifa University of Science and Technology Abu Dhabi, United Arab Emirates

${ }^{2}$ Department of Nuclear Engineering, Kyung Hee University, Republic of Korea

${ }^{3}$ Radiation Science and Engineering Center, Department of Mechanical and Nuclear Engineering, Penn State University, USA

Saeed.alameri@ku.ac.ae, Mohammad.alrwashdeh@ku.ac.ae, Philip.beeley@ku.ac.ae, Mhkim@khu.ac.kr,kunlu@engr.psu.edu

\begin{abstract}
In 2010, the Department of Nuclear Engineering at Khalifa University of Science and Technology (NUCE) established the MSc degree in Nuclear Engineering. This program was established to support the United Arab Emirates (UAE) emerging civil nuclear energy program and produce graduate engineers capable of supporting the safe construction, operation, maintenance and eventual decommissioning of the UAE nuclear reactors. In order to enhance and consolidate classroom teaching, an overseas "Field Trip" module was integrated into the MSc curriculum in order to provide practical exercises, demonstrations and site visits. With respect to the consolidation of reactor physics teaching in particular, the field trips over the past 9 years have utilized mainly the AGN Zero Power reactor at Kyung Hee University (2012-2015) and the Breazeale TRIGA reactor at Penn State University (2017-2018). In both cases students gained "hands-on" supervised experience in classical reactor experiments, shielding measurements, health physics and radiological protection control, and radioanalytical measurement methods, such as neutron activation analysis. At Penn State University, the experiments were extended to surveillance measurements, taking advantage of the facilities specialized modules in nuclear security.

This paper provides details of the arrangements made for the field trips and the learning outcomes these practical arrangements helped to satisfy meeting the overall degree outcomes. The case study will also illustrate where a nuclear energy newcomer State can take advantage of international collaborations without the need to invest in a national research reactor.
\end{abstract}

KEYWORDS: Reactor Physics Education, Field Trips, Research Reactors

\footnotetext{
*Corresponding author: saeed.alameri@ku.ac.ae
} 


\section{INTRODUCTION}

In the past 9 years there have been several academic field trip programs introduced to support the Khalifa University MSc degree in nuclear engineering (NUCE), especially with respect to experimental reactor physics, radiation metrology and radiological protection as well as the management of safety, security and safeguards. This strategy involves giving students, and faculty practical experience in areas ranging from reactor physics experiments, radio-isotopic analysis, shielding, and radiation protection [1]. The MSc in NUCE gives candidates the opportunity to deepen their knowledge in the broad field of nuclear engineering and contribute to the process of discovery and knowledge creation in order to conduct original research within their thesis projects. Candidates for this degree are taught and supervised by experienced faculty and are expected to demonstrate initiative in their approach and innovation in their work. In addition to successfully completing the taught course component of the program, candidates prepare and present a thesis in their chosen area. Research may be undertaken in several topics corresponding to the areas proposed by faculty. The educational goals of the MSc in Nuclear Engineering program are to produce graduates who: [1] Advance professionally and be recognized as leaders in their chosen fields; [2] Apply their technical expertise to address the needs of society in critical, creative, and technical skills and [3] Further develop their knowledge and skills through graduate education and professional schools. The MSc curriculum flow chart in NUCE is presented in Figure 1. With respect to the field trip, the practical experience gained by the students enhances their understanding of the undergraduate level bridging courses (NUCE 301, 302, 303 and 401), and MSc Core courses (NUCE 601, 602, 603 and 606) as well as providing them with opportunities to apply their knowledge in the elective courses (NUCE 611614, and NUCE 621-625) and their thesis (NUCE 699).

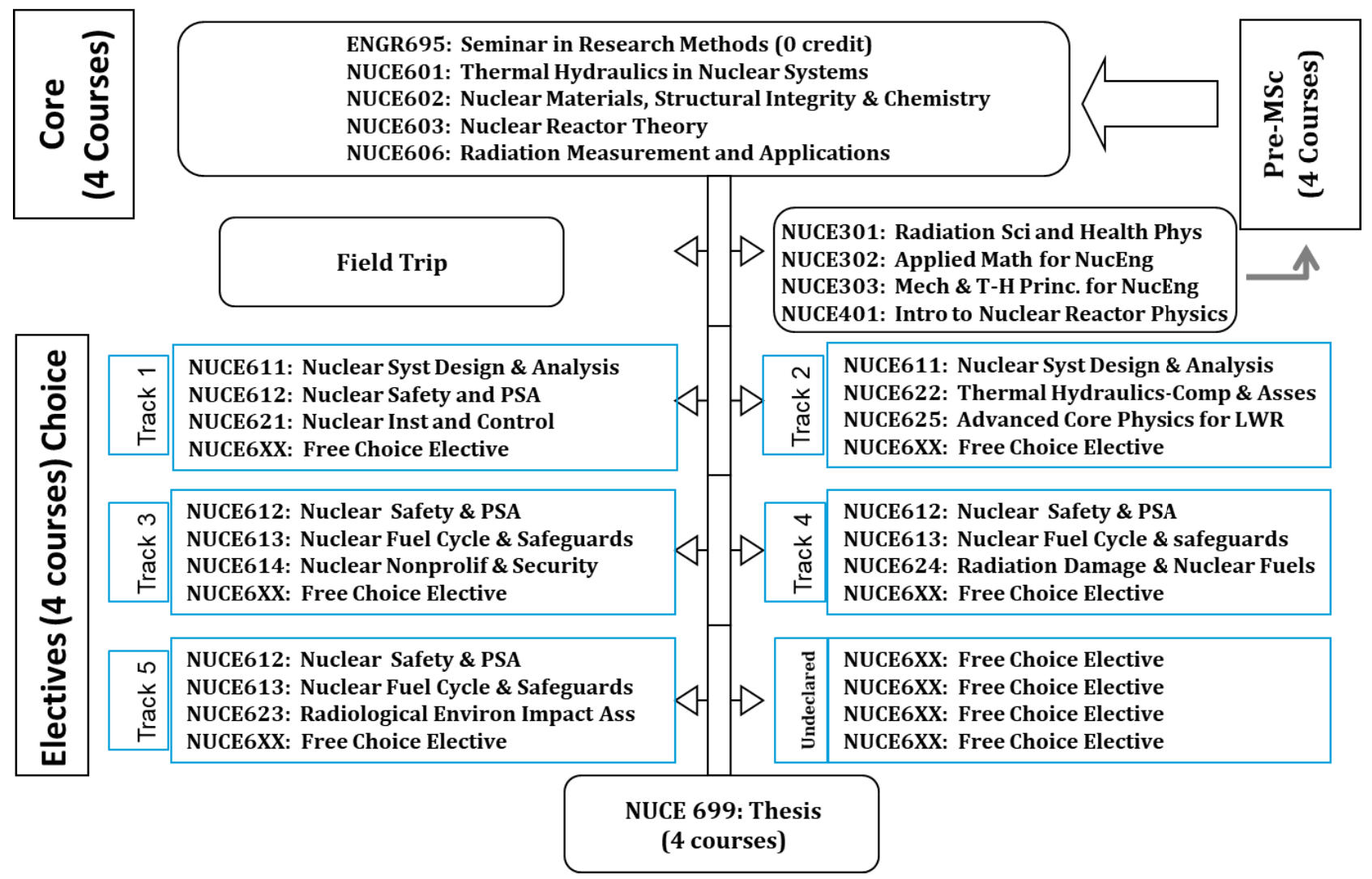

Figure 1. Summary of MSc in NUCE Degree Program Structure and Requirements 


\section{NUCE MSc Fields Trips}

The MSc field trips include practical work at research reactor facilities but also visits to power reactors, fuel fabrication facilities, research centers, regulators (KINS in Korea and NRC in the USA) and supply chain companies supporting the UAE NPP program (Dusan Heavy Industries, Korea and Westinghouse I\&C, USA). The research reactor institutions include National Tsing Hua University (THOR TRIGA reactor), Kyung Hee University (AGN reactor) [1] and Korea Atomic Energy Research Institute (KAERI Hanaro reactor) [2], Penn State University TRIGA reactor [3], and looking for future cooperation with Jordan Research and Training Reactor (JRTR) [4]. The NUCE outreach program main target is ensuring that high quality practical experience can be disseminated to consolidate classroom theory and produce a superlative cadre of young engineers for the Nation. Key Characteristics of these research reactor facilities used for these practical exercises are given in Table I.

Table I. Research Reactors: Characteristics [5]

\begin{tabular}{|l|l|l|l|l|l|}
\hline Characteristic Reactor & HANARO & THOR TRIGA & JRTR & AGN-201K & TRIGA \\
\hline Thermal Power $(\mathbf{M W})$ & 30 & 2 & 5 & $1 \times 10^{-5}$ & 1 \\
\hline Max Thermal Flux (n/cm $/ \mathbf{s})$ & $4.5 \times 10^{14}$ & $3.6 \times 10^{13}$ & $1.45 \times 10^{14}$ & $4.5 \times 10^{8}$ & $3.3 \times 10^{13}$ \\
\hline Max Fast flux (n/cm $/ \mathbf{s})$ & $2.0 \times 10^{14}$ & $6.0 \times 10^{12}$ & $2.38 \times 10^{13}$ & $6.8 \times 10^{8}$ & $3.0 \times 10^{13}$ \\
\hline Reflector Material & $\mathrm{D}_{2} \mathrm{O}$ & $\mathrm{H}_{2} \mathrm{O}$, Graphite & $\mathrm{Be}+\mathrm{D}_{2} \mathrm{O}$ & Graphite & $\mathrm{H}_{2} \mathrm{O}$ \\
\hline Moderator Material & $\mathrm{H}_{2} \mathrm{O}$ & $\mathrm{H}_{2} \mathrm{O}, \mathrm{ZrH}$ & $\mathrm{H}_{2} \mathrm{O}$ & Polyethylene & $\mathrm{H}_{2} \mathrm{O}, \mathrm{ZrH}$ \\
\hline Coolant Material & $\mathrm{H}_{2} \mathrm{O}$ & $\mathrm{H}_{2} \mathrm{O}$ & $\mathrm{H}_{2} \mathrm{O}$ & None & $\mathrm{H}_{2} \mathrm{O}$ \\
\hline $\begin{array}{l}\text { Control, Safety, Shutdown } \\
\text { Rods Material }\end{array}$ & $\mathrm{Hf}$ & Boral & $\mathrm{B}_{4} \mathrm{C}$ & $\begin{array}{l}\text { UO } \\
\text { Polyethylene }\end{array}$ & $\mathrm{B}_{4} \mathrm{C}$ \\
\hline Location & South Korea & Taiwan & Jordan & South Korea & $\begin{array}{l}\text { United States } \\
\text { of America }\end{array}$ \\
\hline
\end{tabular}

\subsection{Research Reactor Experiments}

The Nuclear Engineering MSc curriculum is required to comply with UAE's qualifications framework plan for higher education [6] and other best practice guidelines [7]. Accordingly, arrangements were made with Kyung Hee University and Penn State University to support the enhancement of traditional reactor physics classroom learning with experimental exercises. The proposed experimental facilitates and timeline are shown below in Table II. Experiments performed with AGN reactor are summarized in Table III.

Table II. Reactor Physics Experimental Proposed Experimental Facilities

\begin{tabular}{|c|c|c|c|}
\hline Course & Participants Institutes & Period & Number of students \\
\hline \hline \multirow{4}{*}{ Reactor Experiment } & $\begin{array}{c}\text { National Tsing Hua } \\
\text { University }\end{array}$ & 1 week & 10 \\
\cline { 2 - 4 } & Penn State University & 1 week & 4 \\
\cline { 2 - 4 } & Kyung Hee University & 2 weeks & 5 \\
\cline { 2 - 4 } & Han Yang University & 1 week & 4 \\
\cline { 2 - 4 } & KAIST & 1 week & 4 \\
\hline
\end{tabular}


Table III. Reactor physics experimental training course using the AGN reactor

\begin{tabular}{|c|c|c|c|}
\hline & Title of Experiments & Activities & Period \\
\hline 1 & $\begin{array}{l}\text { Description of AGN-201K \& } \\
\text { Reactor Operation Practice }\end{array}$ & $\begin{array}{l}\text { Understanding of Reactor Physics } \\
\text { Principles }\end{array}$ & \multirow{6}{*}{ 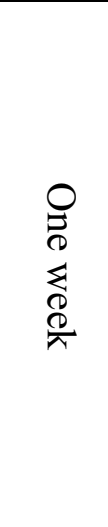 } \\
\hline 2 & $\begin{array}{l}\text { Measurement of Reactor } \\
\text { Period }\end{array}$ & $\begin{array}{l}\text { Measurement Statistic \& Calculation of } \\
\text { Reactivity }\end{array}$ & \\
\hline 3 & $\begin{array}{l}\text { Critical Mass Approach } \\
\text { Experiment }\end{array}$ & 1/M experiment & \\
\hline 4 & Control Rod Calibration & $\begin{array}{l}\text { Period Measurement Method / Swap } \\
\text { Method / Drop Test }\end{array}$ & \\
\hline 5 & Thermal Flux Measurement & $\begin{array}{l}\text { Au Foil Activation / Cd Ratio / MCA } \\
\text { with HPGe Detector }\end{array}$ & \\
\hline 6 & $\begin{array}{l}\text { Reflector Effect / Temperature } \\
\text { Feedback }\end{array}$ & Conditional Change of Reactivity & \\
\hline
\end{tabular}

The course's standard syllabus comprises lectures and practical exercises. The class room teaching is preceded and succeeded by on-job-training modules that are conducted with support of Kyung Hee and Penn State Universities technical staff. The modules before the course refresh participants' knowledge of relevant subject areas in reactor physics and the fundamentals of radiation protection, enabling organizers to identify areas in which participants need further support. The collaboration with both universities is an essential element in reactor physics education program adopted at NUCE. The experimental methods and approaches of reactor physics education and outreach programs have been carefully planned by and conceived by KU faculty in consultation with faculty at the reactor facilities.

The field trip program assists in developing knowledge of applied reactor physics among students, as well as providing channels for them to learn more about the current development issues in the safe and secure operation of nuclear reactors. The field trip program also builds their confidence on the practical applications of safety and security for regulatory compliance. The program also helps to encourage students to choose this field for further studies and in some cases it has indirectly cultivated an interest and opened the student's mind to pursue a career and performing research in reactor physics.

In addition to experiments using the reactor, the students were able to perform nuclear security related search-and-find exercises at Penn State University. They also visited the Penn State University Material Science Research Center and attended demonstrations in the Two Phase Flow Lab. The students visited Westinghouse Global HQ in Pittsburgh, toured the Westinghouse I\&C Electronics fabrication facility and had demonstrations on fuel removal and transfer at the Westinghouse Training Facility at Waltz Mills. The field trip concluded in Washington, D.C. with presentations at the Nuclear Threat Initiative Organization and the Nuclear Regulatory Commission HQ.

\subsection{Future Cooperation with Jordan Atomic Energy Commission}

Looking to the future, NUCE is now collaborating with the Jordanian Atomic Energy Commission and the JRTR (Jordan Research and Training Reactor) to provide practical arrangements for our future MSc student Field Trips. The experiments under consideration in Table IV below include some of those performed with the AGN and TRIGA reactors, but the JRTR provides a much wider scope. 
Table IV. Reactor Physics Experimental Proposed for JRTR

\begin{tabular}{|l|l|}
\hline & Title of Experiments \\
\hline $\mathbf{1}$ & Fuel loading and approach to criticality \\
\hline $\mathbf{2}$ & Excess reactivity measurement \\
\hline $\mathbf{3}$ & Control rod worth measurement \\
\hline $\mathbf{4}$ & Measurement of void reactivity coefficient \\
\hline $\mathbf{5}$ & Measurement of flux distribution \\
\hline $\mathbf{6}$ & Measurement of isothermal temperature reactivity coefficient \\
\hline $\mathbf{7}$ & Neutron power calibration \\
\hline $\mathbf{8}$ & Measurement of power reactivity coefficient \\
\hline $\mathbf{9}$ & Measurement of xenon reactivity \\
\hline $\mathbf{1 0}$ & Neutron Activation Analysis performance test \\
\hline $\mathbf{1 1}$ & Radioisotopes production test \\
\hline $\mathbf{1 2}$ & Radiation surveys to determine shielding effectiveness \\
\hline
\end{tabular}

Research collaborations with JRTR are also envisaged, giving our MSc and $\mathrm{PhD}$ students broader scope in their research choices. NPP operators may also take short internships to the JRTR as part of their overall development plans. These new arrangements will further illustrate the benefits of regional collaborations for the efficient use of research reactors.

\section{CONCLUSIONS}

The achievements made under the fieldtrips strategy for education and training in reactor physics and the other related activities described above resulted in an enhanced curriculum for NUCE MSc program in Nuclear Engineering at Khalifa University. Key targets have been realized and significant work programs are progressing. It is important now to build on this success and continue to move forward with respect to the use of JRTR for education and research.

\section{ACKNOWLEDGMENTS}

This work was supported by Khalifa University of Science and Technology Grant, FSU 8474000067. The authors would like to thank Penn State University, National Tsing Hua University, Kyung Hee University, and Korea Atomic Energy Research Institute for providing KU students with the necessary resources for performing the calculations and experiments needed to assist them in developing the knowledge of applied reactor physics.

\section{REFERENCES}

1. M.H. Kim, "Zero power reactor AGN-201K for university education," European Research Reactor Conference (RRFM), Brussel, Belgium, Mar 13-17, pp. 281-286, 2016.

2. J.J. Ha, I.C. Lim, S.Y. OH, S. WU. "Research Reactor: a Powerhouse of Nuclear Technology in Korea," International Atomic Energy Agency, Division of Physical and Chemical Sciences and Division of Nuclear Fuel Cycle and Waste Technology, Vienna (Austria); [1 CD-ROM]; ISBN 97892-0-184610-5; Worldcat; 2012.

3. Penn State College of Engineering, Radiation Science and Engineering Center, https://www.rsec.psu.edu/Penn_State_Breazeale_Reactor.aspx , Pennsylvania, USA.

4. Jordan Research and Training Reactor, http://jrtr.gov.jo/?AspxAutoDetectCookieSupport=1 , Irbid, Jordan. 
5. IAEA Research Reactor Database, 2009-2019, https://nucleus.iaea.org/rrdb/RR/Reactor Search.aspx?filter $=0$, Vienna Austria.

6. A.A. Solodov, P.A. Beeley, "Khalifa University Initiatives in Human Resource Development for the UAE Nuclear Energy Programme," IAEA International Conference on Nuclear Knowledge Management Challenges and Approaches, Proceedings: ISBN 978-92-0-108818-5, pp. 84-87, 2018.

7. U. Ugbor, K. Peddicord, J. Dies, P. Beeley, V. Artisyuk, "Establishing Sustainable Nuclear Education: Education Capability Assessment and Planning (ECAP) Assist Mission", IAEA International Conference on Nuclear Knowledge Management Challenges and Approaches, Proceedings: ISBN 978-92-0-108818-5, pp. 570-573, 2018. 